\title{
Correction to: Impacts of climate change on hurricane flood hazards in Jamaica Bay, New York
}

\author{
Reza Marsooli ${ }^{1}$ (D) $\cdot$ Ning Lin $^{2}$ \\ Published online: 18 December 2020 \\ (C) The Author(s) 2020
}

\section{Correction to: Climatic Change \\ https://doi.org/10.1007/s10584-020-02932-x}

The original article has been corrected. The funding information has been updated.

\section{Funding}

This material is based upon work supported by the National Science Foundation (grants 1520683 and 1854993) and the High Meadows Environmental Institute of Princeton University. The first author is also supported by an internal research funding from School of Engineering and Science at Stevens Institute of Technology. The first author was formerly an associate research scholar in the Department of Civil and Environmental Engineering at Princeton University. The storm datasets were generated by Kerry Emanuel (from MIT) for our previous Structures of Coastal Resilience design project (http://structuresofcoastalresilience.org). The datasets and simulations presented here have also been applied by our design team (led by Guy Nordenson at Princeton University) to develop flood mitigation strategies for Jamaica Bay (http://www.princeton.edu/cee/ research/head-bay-coastal-resilience-jamaica-bay_2018-12-5). The authors also thank three anonymous reviewers for their constructive comments.

Publisher's note Springer Nature remains neutral with regard to jurisdictional claims in published maps and institutional affiliations.

The online version of the original article can be found at https://doi.org/10.1007/s10584-020-02932-X

\section{Reza Marsooli}

rmarsool@stevens.edu

1 Department of Civil, Environmental, and Ocean Eng, Stevens Institute of Technology, Hoboken, NJ, USA

2 Department of Civil and Environmental Eng, Princeton University, Princeton, NJ, USA 